07,17

\title{
Высокотвердая керамика на основе карбида бора и производных фуллерита
}

\author{
() Д.А. Овсянников ${ }^{1}$, М.Ю. Попов ${ }^{1-3}$, С.А. Перфиилов ${ }^{1}$, В.М. Прохоров ${ }^{1,2}$, \\ Б.А. Кульницкий ${ }^{1,2}$, И.А. Пережогин ${ }^{1,4}$, В.Д. Бланк ${ }^{1-3}$ \\ ${ }^{1}$ Технологический институт сверхтвердых и новых углеродных материалов, \\ Москва, Троицк, Россия \\ ${ }^{2}$ Московский фризико-технический институт (Государственный университет), \\ Долгопрудный, Россия \\ ${ }^{3}$ Национальный исследовательский технологический университет „МИСиС“, \\ Москва, Россия \\ ${ }^{4}$ Московский государственный университет им. М.В. Ломоносова, \\ Москва, Россия \\ E-mail: dao@tisnum.ru
}

(Поступила в Редакцию 20 июля 2016 г.)

Получен новый тип керамики на основе производных фаз фуллерита и $\mathrm{B}_{4} \mathrm{C}$. Материал синтезирован при температуре $1500 \mathrm{~K}$ и относительно низком давлении $4 \mathrm{GPa}$, обладает высокой твердостью $45 \mathrm{GPa}$ и трещиностойкостью $15 \mathrm{MPa} \cdot \mathrm{m}^{1 / 2}$.

Работа выполнена при финансовой поддержке Министерства образования и науки Российской Федерации, по Соглашению № 14.577.21.0090 от 22.07.2014 г. (Проект ID RFMEFI57714X0090).

DOI: 10.21883/FTT.2017.02.44055.302

\section{1. Введение}

Карбид бора $\left(\mathrm{B}_{4} \mathrm{C}\right)$ обладает высокими механическими характеристиками, прежде всего твердостью, износостойкостью, высокими модулями упругости $[1,2]$. Кроме того, относительно низкая плотность в сочетании с высокими механическими характеристиками обусловливают широкое использование этого материала. Керамика на основе $\mathrm{B}_{4} \mathrm{C}$ применяется в качестве режущего инструмента, шлифовальных порошков, износостойких покрытий. Основным методом получения керамики на основе $\mathrm{B}_{4} \mathrm{C}$ является горячее прессование при температуре около $2300 \mathrm{~K}[3,4]$. Также широко используется для получения $\mathrm{B}_{4} \mathrm{C}$ керамики метод спекания в искровой плазме [5]. Однако, несмотря на высокие твердость и износостойкость, $\mathrm{B}_{4} \mathrm{C}$ обладает невысокой прочностью и трещиностойкостью. Для увеличения прочностных характеристик керамики на основе $\mathrm{B}_{4} \mathrm{C}$ при спекании материала используются различные виды добавок, повышающих пластичность и трещиностойкость материала. Недавнее открытие каталитического синтеза $3 D$-полимеризованного фуллерита [6] предоставляет широкие возможности использования фуллерена для получения нового класса углеродных материалов. Керамика на основе углерода является одновременно легкой, прочной и температуростойкой [7,8]. Таким образом, актуальным является создание керамики на основе $\mathrm{B}_{4} \mathrm{C}$ и углеродного материала в качестве связки. Примером может служить работа [9], где была получена высокотвердая керамика на основе зерен $\mathrm{B}_{4} \mathrm{C}$ и углеродной фазы (производных фуллерита) в качестве связующей композиции. Под производными фуллерита в работе [9] подразумевается материал, полученный из фуллерена в условиях высоких давлений и температур в присутствии катализатора $\mathrm{CS}_{2}$. В работе было показано, что при синтезе керамического материла $\mathrm{B}_{4} \mathrm{C}$ с фуллереном в соотношении 50/50 vol.\% синтезируемый материал обладает высокой степенью однородности и характеризуется отсутствием трещин или объемных дефектов [9]. В данной работе была повышена температура синтеза материала на основе $\mathrm{B}_{4} \mathrm{C}-\mathrm{C}_{60}$ в присутствии катализатора $\mathrm{CS}_{2}$, и, как следствие, были получены новые структуры производных фуллерита, отличные от представленных в [9], что привело к изменению механических характеристик керамики.

\section{2. Методика проведения эксперимента}

Изготовление керамического материала на основе $\mathrm{B}_{4} \mathrm{C}$ и производных фаз фуллерита было осуществлено при помощи механического помола $\mathrm{B}_{4} \mathrm{C}$ с фуллереном $\mathrm{C}_{60}$ в планетарной мельнице АГО $2 \mathrm{~V}$ со стальными стаканами и шарами диаметром $10 \mathrm{~mm}$. Концентрация $\mathrm{C}_{60}$ составляла $50 \mathrm{vol} \%$ \% порошковой смеси. В процессе обработки был получен порошок с равномерным распределением углеродных кластеров. После размола порошок был спрессован в таблетки и спекался в ячейке высокого давления типа „наковальня с лункой“. Спекание проводилось при давлении $4 \mathrm{GPa}$ и температуре $1500 \mathrm{~K}$. В качестве вещества, обеспечивающего каталитический синтез углеродной матрицы из фуллерена, 


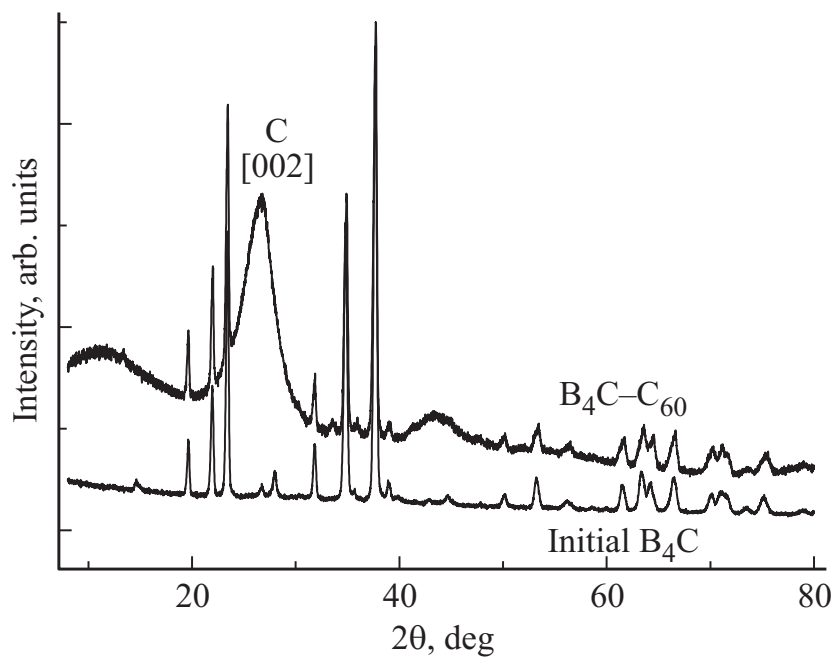

Pис. 1. Дифрактограмма образца $\mathrm{B}_{4} \mathrm{C}-50 \% \mathrm{C}_{60}$, спеченного при давлении $4 \mathrm{GPa}$ и температуре $1500 \mathrm{~K}$. Для сравнения приведена дифрактограмма исходного порошка $\mathrm{B}_{4} \mathrm{C}$. использовался $\mathrm{CS}_{2}$. Полученные образцы имели форму дисков с размерами $4 \times 18 \mathrm{~mm}$. Плотность полученных образцов составляла $2.2 \pm 0.05 \mathrm{~g} / \mathrm{cm}^{3}$. Чистота исходных материалов $\mathrm{C}_{60}$ и $\mathrm{CS}_{2}$, использованных в исследовании, составляла $99.9 \%$.

Структура образцов исследовалась с помощью электронного микроскопа JEM 2010, в том числе с использованием метода спектроскопии потерь энергии электронов (СПЭЭ). Для рентгенофазового анализа использовался универсальный дифрактометр Empyrean. Исследования спектров комбинационного рассеяния света (КРС) проводилось с помощью КРС микроскопа in Via с длиной возбуждения $532 \mathrm{~nm}$.

Были измерены механические свойства образцов: микротвердость (измерялась методом индентирования пирамидой Виккерса на установке DuraScan), трещиностойкость (вычисление по длине трещин вокруг отпечатка); прочностные характеристики (изгиб, сжатие) - на испытательной машине INSTRON 5982.
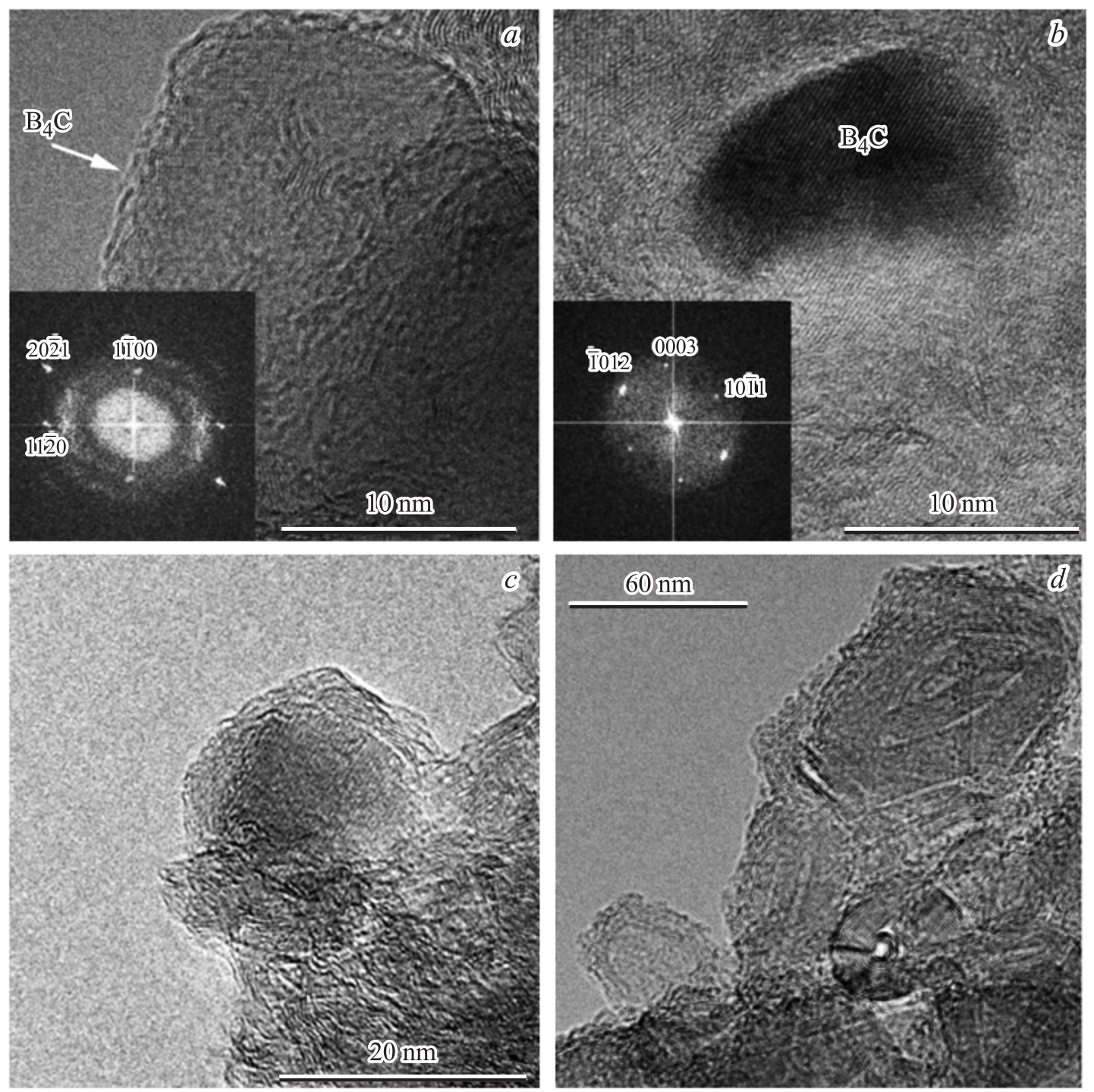

Рис. 2. ПЭМ-изображения образцов $\mathrm{B}_{4} \mathrm{C}-50 \% \mathrm{C}_{60}$. 


\section{3. Экспериментальные результаты и их обсуждение}

3.1. Структура и фазовый состав образцов. Рентгенофазовый анализ полученных образцов показал, что дифракции исходного $\mathrm{B}_{4} \mathrm{C}$ и полученных образцов (рис. 1) практически не отличаются, за исключением того, что в дифрактограммах $\mathrm{B}_{4} \mathrm{C}-50 \% \mathrm{C}_{60}$ присутствует широкий дифракционный пик (полуширина $5 \mathrm{deg}$ ), соответствующий графитоподобному аморфному углероду [002].

По данным исследования, проведенного с помощью ПЭМ, в образце встречаются как одиночные частицы $\mathrm{B}_{4} \mathrm{C}$, так и агломераты, состоящие из нескольких частиц $\mathrm{B}_{4} \mathrm{C}$. Кроме того, были обнаружены углеродные структуры, отличные от наблюдавшихся в работе [9].

На рис. 2, а показана частица карбида бора, на поверхности которой видны слои углерода. На вставке показана дифракционная картина, проиндицированная в гексагональных координатах (ось зоны [0001]). На рис. 2, $b$ показан агломерат, состоящий из нескольких частиц $\mathrm{B}_{4} \mathrm{C}$ (одна из них промаркирована). На вставке показана дифракционная картина (ось зоны $[\overline{1} 2 \overline{1} 0]$ ). На рис. 2, c показана частица $\mathrm{B}_{4} \mathrm{C}$, покрытая несколькими графитоподобными слоями.

В образцах, полученных при температуре $1300 \mathrm{~K}$ в работе [9], на дифракционных снимках ПЭМ производных фуллерита были обнаружены дифракционные плоскости, расположенные под углом $70^{\circ}$. В образцах, полученных при более высокой температуре $1500 \mathrm{~K}$ в данной работе, таких плоскостей не было обнаружено. Вместо $70^{\circ}$-ных плоскостей наблюдаются разнообразные луковичные структуры, а также полосы, состоящие из графитоподобных слоев (рис. $2, d$ ).

На рис. 3 приведены СПЭЭ-спектры, измеренные в исследуемом образце (спектры 1 и 2), а также, для сравнения, спектры графита (3) и фуллерена $\mathrm{C}_{60}$ (4), измеренные на том же самом оборудовании. Спектры 1 и 2 близки к спектру графита, отличаясь от него меньшим контрастом пиков на 285 и $292 \mathrm{eV}$, характерных для графита, а также небольшими пиками в области минимума вблизи $288 \mathrm{eV}$. Присутствие этих небольших пиков в спектре может свидетельствовать о наличии молекул фуллерена (или их фрагментов), однако они не всегда могут быть точно определены в данном эксперименте, с учетом фона и энергетического разрешения. Еще одно отличие спектров 1 и 2 от графита заключается в следующем: в графите максимальная интенсивность наблюдается на $292 \mathrm{eV}$, а в спектрах 1 и 2 она соответствует примерно $300 \mathrm{eV}$, что более характерно для $\mathrm{C}_{60}$. В спектре 2 , как и в спектрах фуллерита и графита, отдельно заметен пик на $292 \mathrm{eV}$, при этом он значительно ниже, чем в спектре графита. Материал, с которого снят спектр, отличается и от графита, и от фуллерита, однако, по всей видимости, наследует определенные особенности структуры фуллерита. Данные особенности СПЭЭ спектры, в частности, обусловливают общее название углеродных

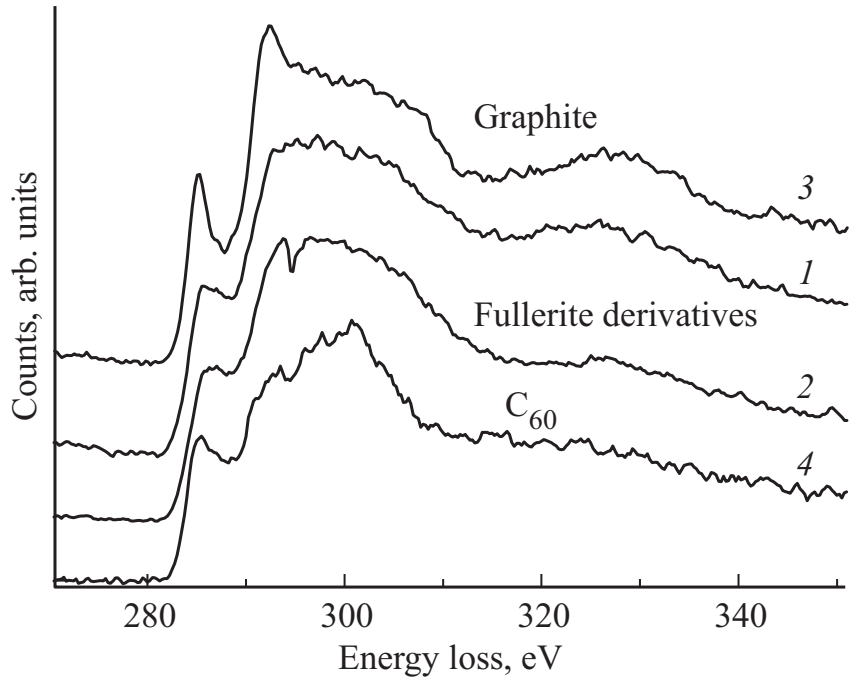

Рис. 3. СПЭЭ-спектры, полученные в исследуемом образце (спектры 1 и 2). Для сравнения приведены спектры графита (3) и фуллерита $\mathrm{C}_{60}(4)$.

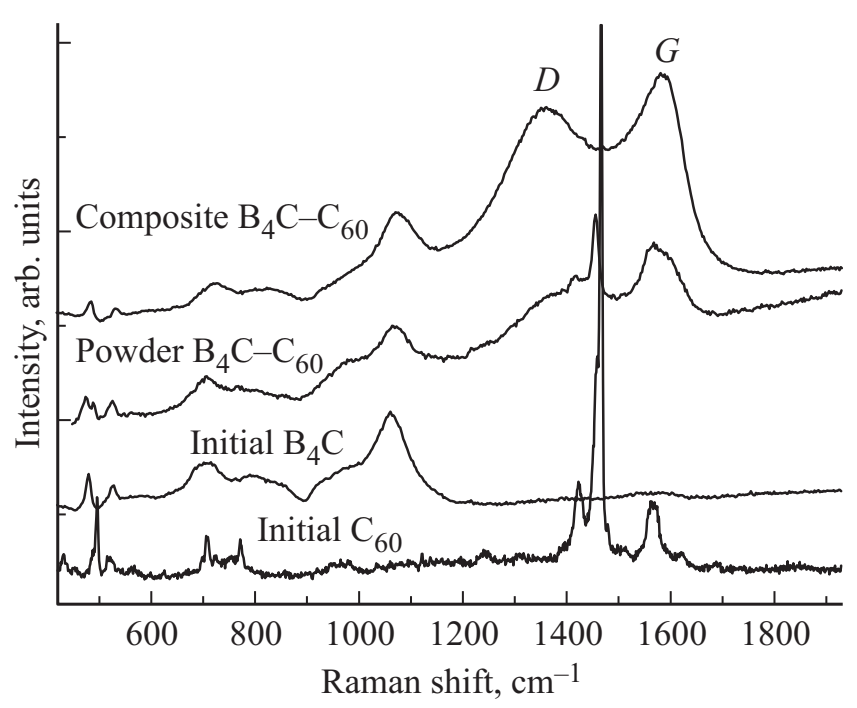

Рис. 4. КРС-спектры спеченного образца керамики $\mathrm{B}_{4} \mathrm{C}-\mathrm{C}_{60}$, образца порошка композитного материала, полученного после механоактивации смеси $\mathrm{B}_{4} \mathrm{C}$ и фуллерена $\mathrm{C}_{60}$ при возбуждении лазером с длиной волны $532 \mathrm{~nm}$. Спектры исходных $\mathrm{B}_{4} \mathrm{C}$ и фуллерена приведены для сравнения.

структур (производные фаз фуллерита), наблюдаемых как в данной работе, так и в работе [9].

КРС-спектры (возбуждение лазером с длиной волны $532 \mathrm{~nm}$ ) исходного $\mathrm{B}_{4} \mathrm{C}$ и образца порошка наноматериала, полученного после механоактивации смеси $\mathrm{B}_{4} \mathrm{C}$ и фуллерена $\mathrm{C}_{60}$, а также спеченной керамики представлены на рис. 4. В КРС-спектрах порошка, полученного в результате механоактивации $\mathrm{B}_{4} \mathrm{C}$ и фуллерена $\mathrm{C}_{60}$, наблюдаются полосы исходного $\mathrm{B}_{4} \mathrm{C}$, а также тангенциальные моды $\mathrm{C}_{60}$. В КРС-спектрах спеченного образца 
$\mathrm{B}_{4} \mathrm{C}-\mathrm{C}_{60}$ наблюдаются полосы исходного $\mathrm{B}_{4} \mathrm{C}$, а также широкие $G$ и $D$ пики углерода.

3.2. Механические свойства образцов. Твердость образцов была измерена пирамидой Виккерса с помощью твердомера DuraScan при нагрузках на индентор от 5 до $100 \mathrm{H}$. Значение твердости, полученное данным методом, оказалось равным $45 \pm 5 \mathrm{GPa}$ для образцов $\mathrm{B}_{4} \mathrm{C}-\mathrm{C}_{60}$. Результат измерений не зависел от нагрузки на индентор. Для сравнения, твердость образцов, спеченных при температуре $1300 \mathrm{~K}$ [9], составляла $60 \mathrm{GPa}$. Данное отличие обусловлено тем, что при повышении температуры в настоящих экспериментах наблюдается несколько другая структура продуктов трансформации фуллерита, чем в работе [9].

Следует обратить внимание, что полученное значение твердости для $\mathrm{B}_{4} \mathrm{C}-\mathrm{C}_{60}$ превышает твердость $\mathrm{B}_{4} \mathrm{C}$ 35-40 GPa [1]. Этот эффект обусловлен тем, что механические свойства композитной керамики на основе продуктов трансформации фуллерита и $\mathrm{B}_{4} \mathrm{C}$ определяются как механическими свойствами $\mathrm{B}_{4} \mathrm{C}$, так и производными фазами фуллерита, а также наличием химических связей между этими компонентами. Твердость производных фаз фуллерита, по данным работы [9], составляет около $100 \mathrm{GPa}$, что объясняет достаточно высокую твердость композита $\mathrm{B}_{4} \mathrm{C}-\mathrm{C}_{60}$.

Трещиностойкость $K_{1 C}$ вычислялась методом, изложенным в работе [10], по нагрузке на индентор и отношению длин трещин, образовавшихся при индентировании, к длине диагонали отпечатка. Первые трещины, являющиеся продолжением диагоналей отпечатка, появлялись при нагрузке на индентор $100 \mathrm{H}$. Трещиностойкость образцов $\mathrm{B}_{4} \mathrm{C}-\mathrm{C}_{60}$ составила $K_{1 C}=15 \mathrm{MPa} \cdot \mathrm{m}^{1 / 2}$.

Для образцов $\mathrm{B}_{4} \mathrm{C}-\mathrm{C}_{60}$ были проведены испытания на прочность на изгиб (3 точечный изгиб) и на сжатие. Прочность на изгиб образцов $\mathrm{C}_{60}-\mathrm{B}_{4} \mathrm{C}$ составила $550 \pm 5 \mathrm{MPa}$, прочность на сжатие составила $2250 \pm 20 \mathrm{MPa}$.

\section{4. Заключение}

Получен и исследован новый углерод-композитный керамический материал на основе $\mathrm{B}_{4} \mathrm{C}$. Композит синтезирован при относительно низком давлении $4 \mathrm{GPa}$ в результате каталитического синтеза продуктов трансформации фуллерита и карбида бора. Структура композита, полученного в данной работе спеканием при $1500 \mathrm{~K}$, отличается наличием луковичных структур вместо дифракционных плоскостей, расположенных под углом $70^{\circ}$, формирующихся при более низкой температуре $1300 \mathrm{~K}$ [9]. Кроме изменения структуры углеродной составляющей, повышение температуры спекания снижает твердость образцов с 60 до $45 \mathrm{GPa}$ При этом образцы обладают высокой трещиностойкостью $\left(15 \mathrm{MPa} \cdot \mathrm{m}^{1 / 2}\right)$, прочностью и низкой плотностью $2.2 \mathrm{~g} / \mathrm{cm}^{3}$.

\section{Список литературы}

[1] F. Th'evenot. J. Eur. Ceram. Soc. 6, 205 (1990).

[2] V. Domnich, S. Reynaud, R.A. Haber, M. Chhowalla. J. Am. Ceram. Soc. 94, 3605 (2011).

[3] H.W. Kim, Y.H. Koh, H.E. Kim. J. Mater. Res. 15, 2431 (2000).

[4] J. Deng, J. Zhou, Y. Feng, Z. Ding. Ceram. Int. 28, 425 (2002).

[5] K.H. Kim, J.H. Chae, J.S. Park, J.P. Ahn, K.B. Shim. J. Ceram. Proc. Res. 10, 716 (2009).

[6] M. Popov, V. Mordkovich, S. Perfilov, A. Kirichenko, B. Kulnitskiy, I. Perezhogin, V. Blank. Carbon 76, 250 (2014).

[7] V.D. Blank, S.G. Buga, N.R. Serebryanaya, G.A. Dubitsky, B. Mavrin, M.Y. Popov, R.H. Bagramov, V.M. Prokhorov, S.A. Sulynov, B.A. Kulnitskiy, Y.V. Tatyanin. Carbon 36, 665 (1998).

[8] M. Popov, R. Gayazov, F. Khadzhiyskiy, V. Medvedev, V. Krivtsun, A. Kirichenko, B. Kulnitskiy, I. Perezhogin, E. Tyukalova, V. Blank. J. Appl. Phys. 115, 153506 (2014).

[9] M. Popov, S. Perfilov, D. Ovsyannikov, B. Kulnitskiy, I. Perezhogin, E. Tyukalova, V. Prokhorov, I. Maslenikov, E. Skryleva, Yu. Parkhomenko, V. Blank. MRS Commun. 5, 71 (2015).

[10] Е.М. Морозов, М.В. Зернин. Контактные задачи механики разрушения. Машиностроение, М. (1999). 544 с. 